\title{
An Improved CoCoSo Method with a Maximum Variance Optimization Model for Cloud Service Provider Selection
}

\author{
Han Lai ${ }^{1,2}$, Huchang Liao ${ }^{2 *}$,Zhi Wen ${ }^{2}$, Edmundas Kazimieras Zavadskas $^{3}$, Abdullah Al-Barakati ${ }^{4}$ \\ ${ }^{1}$ Chongqing Engineering Laboratory for Detection, Control and Integrated System, Chongqing Technology and Business \\ University \\ Chongqing 400067, China \\ E-mail.laihan_ctbu@126.com
}

${ }^{2}$ Business School, Sichuan University

Chengdu 610064, China

E-mails.*liaohuchang@163.com;wenzhi_456789@163.com

*Corresponding author

${ }^{3}$ Institute of Sustainable Construction, Vilnius Gediminas Technical University

Sauletekio al. 11, Vilnius LT-10223, Lithuania

E-mail.edmundas.zavadskas@vgtu.lt

${ }^{4}$ Faculty of Computing and Information Technology, King Abdulaziz University

Jeddah 21589, Saudi Arabia

E-mail.aaalbarakati@kau.edu.sa

cross $^{\text {ref }}$ http://dx.doi.org/10.5755/j01.ee.31.4.24990

With the rapid growth of available online cloud services and providers for customers, the selection of cloud service providers plays a crucial role in on-demand service selection on a subscription basis. Selecting a suitable cloud service provider requires a careful analysis and a reasonable ranking method. In this study, an improved combined compromise solution (CoCoSo) method is proposed to identify the ranking of cloud service providers. Based on the original CoCoSo method, we analyze the defects of the final aggregation operator in the original CoCoSo method which ignores the equal importance of the three subordinate compromise scores, and employ the operator of "Linear Sum Normalization" to normalize the three subordinate compromise scores so as to make the results reasonable. In addition, we introduce a maximum variance optimization model which can increase the discrimination degree of evaluation results and avoid inconsistent ordering. A numerical example of the trust evaluation of cloud service providers is given to demonstrate the applicability of the proposed method. Furthermore, we perform sensitivity analysis and comparative analysis to justify the accuracy of the decision outcomes derived by the proposed method. Besides, the results of discrimination test also indicate that the proposed method is more effective than the original CoCoSo method in identifying the subtle differences among alternatives.

Keywords: Multi-Criteria Decision Making; Cloud Service Provider Selection; Combined Compromise Solution (Cocoso); Maximum Variance; Discrimination Degree.

\section{Introduction}

Cloud computing is an emerging technology for providing software, platform and infrastructural resources on demand over the Internet, enabling consumers to avoid initial expenses, reduce operating costs, and enhance responses by acquiring the services and infrastructural resources instantaneously in an elastic manner, so that consumers can focus more time on innovation and the creation of business value. With the rapid development of cloud computing, cloud service providers (CSPs) such as Amazon, Google, Microsoft have launched a wide variety of cloud services, which allows consumers to handle large datasets running on remote servers (i.e., cloud) without installing and executing on local computers anymore (Varghese \& Buyya, 2018). However, with the rapid growth of available online cloud services and providers, it becomes a challenge for consumers to choose the best service provider based on their operational requirements, financial constraints and long-term performance (Al-Faifi et al., 2019; Alshehri, 2019; Buyukozkan et al., 2018).

Selecting a suitable CSP requires a careful analysis and a reasonable ranking method. It can be viewed as a multicriteria decision-making (MCDM) problem since it involves the intrinsic relationships among the quality of service (QoS) criteria. The studies on the CSP selection based on MCDM have gained huge momentum in recent years (Alabool et al., 2018). For example, the SAW (Simple Additive Weighting) was widely adopted for cloud service selection (Zhao et al., 2012; Qu et al., 2013). However, the SAW is a simple weighting approach that was generally used to solve single dimensional decision problems requiring low decision accuracy. Garg et al. (2013) proposed a cloud service quality 
ranking method based on the AHP (Analytic Hierarchy Process). Choi and Jeong (2014) gave a quality evaluation method for cloud computing service selection based on the ANP (Analytic Network Process). Nawaz et al. (2018) applied the BWM (Best-Worst Method) for cloud service selection. Sidu and Singh (2019) proposed a PROMETHEE (Preference Ranking Organization Method for Enrichment Evaluations)-based method for the selection of trustworthy cloud database servers. Abourezq and Idrissi (2014) applied the ELECTRE (Elimination etchoix traduisant la realite)based method to determine which cloud service meets the best users' requirements. Costa et al. (2013) proposed an MCDM method for evaluating cloud services based on the MACBETH (Measuring Attractiveness by a Categorical Based Evaluation Technique). However, these methods involve pairwise comparisons, which are complex and timeconsuming, and are not suitable for the situation with large number of criteria and alternatives.

For solving the MCDM problem of cloud service selection, it is needed to deal with the compromise of QoS values of cloud services with respect to different or even conflicting evaluation criteria. In many cases, the decisionmaking process can be aided by a comprehensive analysis from the perspective of the basic properties of non-inferior or compromise solutions (Yu, 1973). At present, MCDM methods of cloud service selection have been researched to find a compromise solution. For example, the TOPSIS (Technique for Order Preference by Similarity to Ideal Solution) was suggested by Singh and Sidhu (2017) to determine the trustworthiness degrees of cloud service providers based on a compromise solution. Serrai et al. (2016) exploited the VIKOR (VIseKriterijumska Optimizacija I Kompromisno Resenje), which determines a compromise solution with a maximum group utility value and a minimum 'individual' regret value to rank the obtained skyline web services. Buyukozkan et al. (2018) proposed an integrated framework based on the AHP, VIKOR, MULTIMOORA (Multi-Objective Optimization on the basis of a Ratio Analysis plus the full MULTIplicative form) and COPRAS (Complex Proportional Assessment) to select the most desirable cloud computing technology provider, which deduces a compromise solution with the maximum value of the sum of maximum weighted normalization criteria values and the minimum value of the sum of minimum weighted normalization criteria values. However, when using these methods to solve MCDM problems, the ranking results produced by these methods may change greatly corresponding to the change of weight distributions of criteria. In other words, the reliability and stability of the results produced by these methods are limited (Wen et al., 2019). To improve this limitation, the CoCoSo (Combined Compromise Solution) method, one of the MCDM methods, was proposed by Yazdani et al. (2019b). It integrates the SAW (Afshari et al., 2010), WASPAS (Weighted Aggregated Sum Product Assessment ) (Zavadskas et al., 2012) and MEW (Multiplicative Exponential Weighting) methods (Zanakis et al., 1998) with aggregation strategies. By this method, decision-makers can obtain a multi-faceted compromise solution, which is consistent with the solution obtained by other MCDM methods, such as the VIKOR (Opricovic, 1998), WASPAS (Zavadskas et al., 2012) and MOORA (Multi-Objective Optimization on the basis of Ratio
Analysis) (Brauers \& Zavadskas, 2006) methods. Moreover, the optimal solution screened by the CoCoSo method is not easily affected by the changes of weight distribution of criteria or the deletion/addition of alternatives. These imply that the CoCoSo method is a robust method, which has advantages in reliability and stability of the decision-making results. In addition, the CoCoSo method is easy to understand and has wide applicability, and thus has been extended to different circumstances to solve decision-making problems in various fields (Peng et al., 2019; Yazdani et al., 2019a; Wen et al., 2019).

However, to the best of our knowledge, there is no literature on the application of the CoCoSo method in CSP selection problem. Therefore, this study incorporates the CoCoSo method to evaluate the trustworthiness of CSPs based on available real sample dataset. We dedicate to achieving the following contributions:

(1) We analyze the defects of the final aggregation operator in the original CoCoSo method which ignores the equal importance of the three subordinate compromise scores, and employ the operator of "Linear Sum Normalization" to normalize the three subordinate compromise scores to make the results reasonable;

(2) We propose a new integration function based on a maximum variance optimization model to aggregate the three subordinate compromise scores obtained in the CoCoSo mehtod, so as to increase the differentiation degree of evaluation results and avoid inconsistent ordering;

(3) We apply the proposed new MCDM method to select the optimal CSP, and then highlight the advantages of the proposed method by the sensitive analysis, consistency comparison of ranking results, and discrimination test.

The rest of this paper is organized as follows. First, we introduce the preliminaries of this study. Next, we present the improved CoCoSo method with a maximum variance optimization model. Then, we present a case study that uses the Cloud Armor to analyze the efficiency and reliability based on executing the proposed method and comparing with other MCDM methods. Finally, a conclusion with directions for future work is provided.

\section{Preliminaries}

In this section, we briefly review the literature on the MCDM methods related to the CSP selection, and the implementation steps of the CoCoSo method and its extension. In addition, we summarize the common normalization methods.

\section{Literature Review of the CSP Selection Based on MCDM Methods}

In the past few years, the selection of CSPs based on MCDM methods has been widely concerned on the evaluation and identification of trustworthy CSPs. The MCDM methods used to select CSPs can be classified into four categories: single MCDM methods, fuzzy MCDM methods, hybrid MCDM methods, and fuzzy hybrid MCDM methods. Table 1 lists the related works in terms of these four categories. 
MCDM Method(s) used to Evaluate Cloud Service Provider

\begin{tabular}{|c|c|c|}
\hline Category & MCDM method(s) & Reference(s) \\
\hline \multirow{9}{*}{ Single MCDM } & AHP & $\begin{array}{l}\text { Garg et al., 2013; Ramachandran et al., 2014; } \\
\text { Sun } \text { et al., } 2013\end{array}$ \\
\hline & ANP & Choi \& Jeong, 2014; Ergu \& Peng, 2014 \\
\hline & ELECTRE & Silas et al., 2012 \\
\hline & MAUT (Multi-Attribute Utility Theory ) & Ding et al., 2014 \\
\hline & MACBETH & Costa et al., 2013 \\
\hline & PAPRIKA (Potentially All Pairwise Rankings of All Possible Alternatives) & Alismaili et al., 2016 \\
\hline & PROMETHEE & Sidhu \& Singh, 2019 \\
\hline & SAW & Zhao et al., 2012 \\
\hline & TOPSIS & Ginting et al., 2017 \\
\hline \multirow{10}{*}{$\begin{array}{l}\text { Fuzzy MCDM } \\
\text { method }\end{array}$} & Fuzzy AHP \& fuzzy logic model & Paunovic et al., 2018 \\
\hline & IIVIFS (Improved Interval-Valued Intuitionistic Fuzzy Sets) \& WASPAS & Gireesha et al., 2020 \\
\hline & IFS (Intuitionistic fuzzy set) \& TOPSIS & Mu et al., 2014 \\
\hline & TFN (Triangular fuzzy number) \& AHP & Low \& Chen, 2012 \\
\hline & TFN \& Fuzzy ANP & Le et al., 2014 \\
\hline & TFN \& BWM & Hussain et al., 2020 \\
\hline & TFN \& TOPSIS & Basu \& Ghosh, 2018 \\
\hline & TFN \& VIKOR & Alabool \& Mahmood, 2013 \\
\hline & TrFN(Trapezoidal Fuzzy Number)) \& SAW & Qu et al., 2013 \\
\hline & TNN (Triangular Neutrosophic Numbers) \& AHP & Abdel-Basset et al., 2018 \\
\hline \multirow{9}{*}{$\begin{array}{l}\text { Hybrid MCDM } \\
\text { method }\end{array}$} & AHP \& cloud model & Yang et al., 2018 \\
\hline & AHP \& Cosine Maximization method & Alshehri, 2019 \\
\hline & AHP \& Logic Scoring & Ataş \& Gungor, 2014 \\
\hline & AHP \& TOPSIS & Singh \& Sidhu, 2017 \\
\hline & ANP \& DEMATEL \& TOPSIS & Alimardani et al., 2014 \\
\hline & $\begin{array}{l}\text { ANP \& GRA (Gray Relational Analysis) \& DEMATEL (Decision Making } \\
\text { Trial And Evaluation Laboratory) }\end{array}$ & Huang et al., 2012 \\
\hline & ELECTRE \& Block-Nested Loop Algorithm & Abourezq \& Idrissi, 2014 \\
\hline & BWM \& VIKOR & Serrai et al., 2016 \\
\hline & BWM \& Markov chain method & Nawaz et al., 2018 \\
\hline \multirow{6}{*}{$\begin{array}{l}\text { Fuzzy hybrid } \\
\text { MCDM method }\end{array}$} & BSC (Balanced score card) \& fuzzy Delphi \& Fuzzy AHP & Lee \& Seo, 2016 \\
\hline & AHP and grey TOPSIS & Jatoth et al., 2019 \\
\hline & TFN \& AHP \& WASPAS & Alam et al., 2018 \\
\hline & Rough ANP and rough TOPSIS & Li et al., 2018 \\
\hline & Fuzzy set theory \& TOPSIS \& Dempster-Shafer theory \& Game Theory & Esposito et al., 2015 \\
\hline & IVIF \& AHP \& COPRAS \& MULTIMOORA \& TOPSIS & Buyukozkan et al., 2018 \\
\hline \multicolumn{2}{|c|}{$\begin{array}{l}\text { From Table 1, we can see that most studies have focused } \\
\text { on the use of preference ordering-based methods, such as the } \\
\text { AHP, ANP and BWM, PROMETHEE, ELECTRE, and } \\
\text { MACBETH. But these methods involve pairwise } \\
\text { comparisons, and thus are complex and time-consuming, } \\
\text { especially in the situation with large number of criteria and }\end{array}$} & $\left.\begin{array}{ccc}C_{2} & \cdots & C_{n} \\
x_{12} & \cdots & x_{1 n} \\
x_{22} & \cdots & x_{2 n} \\
\vdots & \ddots & \vdots \\
x_{m 2} & \cdots & x_{m n}\end{array}\right] ; i=1,2, \cdots m ; j=1,2, \cdots, n \cdot(1)$ \\
\hline
\end{tabular}
alternatives. In addition, we can also find that some utility value-based methods such as the TOPSIS, VIKOR, COPRAS have been used in solving the problem of CSP selection from the perspective of the basic properties of noninferior or compromise solutions. These methods have the advantages of the simple calculation, easy to understand, and available of ranking set. But the ranking results produced by these methods may change due to the change of weight distributions of criteria. Therefore, a new CSP selection method should be developed as an effective evaluation synthesis technique to cover the shortage. Outline of the CoCoSo method and its extensions

Yazdani et al. (2019b) proposed the CoCoSo method to deduce compromise solutions for MCDM problems by integrated the SAW, WASPAS and MEW methods with aggregation strategies. After determining the alternatives $\left(A_{1}, A_{2}, \cdots, A_{m}\right)$ and the evaluation criteria $\left(C_{1}, C_{2}, \cdots, C_{n}\right)$, the steps of the CoCoSo method are given as below.

Step 1. Form the initial decision matrix $X$ for $m$ alternatives with respect to $n$ criteria:
Step 2. Based on the idea that the desirability degrees of alternatives are related to the distances between alternatives and negative ideal solutions, we need to normalize the elements in the initial matrix. For "benefit" type criteria such as the CPU processing performance and the Disc storage performance in QoS criteria, the element $r_{i j}$ in the normalized matrix $R_{m \times n}$ are obtained by:

$$
r_{i j}=\frac{x_{i j}-\min _{i} x_{i j}}{\max _{i} x_{i j}-\min _{i} x_{i j}}
$$

For "cost" type criteria such as the network latency and the cost on demand in QoS criteria, the element $r_{i j}$ in the normalized matrix $R_{m \times n}$ are obtained by:

$$
r_{i j}=\frac{\max _{i} x_{i j}-x_{i j}}{\max _{i} x_{i j}-\min _{i} x_{i j}}
$$

Step 3. Using Eqs. (4) and (5) to obtain the sum of weighted comparability sequence $S_{i}$ and power-weighted comparability sequences $P_{i}$ for each alternative, respectively: 
Han Lai, Huchang Liao, Zhi Wen, Edmundas Kazimieras Zavadskas, Abdullah Al-Barakati. An Improved CoCoSo Method...

$$
\begin{gathered}
S_{i}=\sum_{j=1}^{n}\left(w_{j} r_{i j}\right), \text { for } i=1,2, \cdots m \\
P_{i}=\sum_{j=1}^{n}\left(r_{i j}\right)^{w_{j}}, \text { for } \quad i=1,2, \cdots m
\end{gathered}
$$

where $w_{j}$ denotes the weight of the $j$ th criterion and $\sum_{j=1}^{n} w_{j}=1$.

Step 4. Based on the idea of the MULTIMOORA method (Brauers \& Zavadskas, 2010), we can compute the relative priorities of alternatives by the aggregation strategies shown as Eqs. (6)-(8). Eq. (6) expresses the arithmetic mean of sums of the WSM (Weighted Sum Method) and WPM (Weighted Product Method) scores. Eq. (7) signifies a sum of relative scores of WSM and WPM compared to the worst cases. Eq. (8) computes a balanced score of WSM and WPM models. Three subordinate compromise scores are obtained to generate the performance scores of the alternatives.

$$
\begin{aligned}
k_{i 1} & =\frac{S_{i}+P_{i}}{\sum_{i=1}^{m}\left(S_{i}+P_{i}\right)}, \text { for } i=1,2, \cdots m \\
k_{i 2} & =\frac{S_{i}}{\min _{i} S_{i}}+\frac{P_{i}}{\min _{i} P_{i}}, \text { for } i=1,2, \cdots m \\
k_{i 3} & =\frac{\lambda\left(S_{i}\right)+(1-\lambda)\left(P_{i}\right)}{\left(\lambda \max _{i} S_{i}+(1-\lambda) \max _{i} P_{i}\right)}, \text { for } i=1,2, \cdots m
\end{aligned}
$$

In Eq. (8), the value of $\lambda$ (usually $\lambda=0.5$ ) is determined by decision-makers and $0 \leq \lambda \leq 1$.

Step 5. The ranking of all alternatives is determined in descending order of the performance scores of the alternatives:

$$
k_{i}=\left(k_{i 1} k_{i 2} k_{i 3}\right)^{1 / 3}+\frac{1}{3}\left(k_{i 1} k_{i 2} k_{i 3}\right), \text { for } i=1,2, \cdots m
$$

The CoCoSo method is easy to understand and has wide applicability. It has been extended to solve decision-making problems in various fields. For example, Yazdani et al. (2019a) proposed a grey combined compromise solution (CoCoSo-G) method for the supplier selection in construction management. Peng et al. (2019) proposed a Pythagorean fuzzy CoCoSo method for $5 \mathrm{G}$ industry evaluation. Wen et al. (2019) proposed a hesitant fuzzy linguistic CoCoSo method for the selection of third-party logistics service providers in supply chain finance. Ecer et al. (2020) adopted the CoCoSo method to evaluate the sustainability performance of OPEC countries. Zolfani et al. (2019) proposed a structured framework for sustainable supplier selection based on the combined BWM-CoCoSo model.

\section{Normalization Methods}

Converting all performance values of alternatives under each criterion into non-dimensional forms is a crucial step in most MCDM methods. Several normalization methods have been developed (Jahan \& Edwards, 2015). Table 2 shows five well-known normalization techniques (Gardziejczyk \& Zabicki, 2017).

\begin{tabular}{|l|c|c|}
\multicolumn{1}{|c}{ Criteria Normalization Nethods } \\
\hline Normalization method & Benefit criteria & Cost criteria \\
\hline Standardization & $r_{i j}=\frac{x_{i j}-\bar{x}_{j}}{\sigma_{j}}$ & $r_{i j}=-\frac{x_{i j}-\bar{x}_{j}}{\sigma_{j}}$ \\
\hline Vector normalization & $r_{i j}=\frac{x_{i j}}{\sqrt{\sum_{i=1}^{m} x_{i j}^{2}}}$ & $r_{i j}=1-\frac{x_{i j}}{\sqrt{\sum_{i=1}^{m} x_{i j}^{2}}}$ \\
\hline $\begin{array}{l}\text { Linear max } \\
\text { normalization }\end{array}$ & $r_{i j}=\frac{x_{i j}}{x_{j}^{+}}$ & $r_{i j}=1-\frac{x_{i j}}{x_{j}^{+}}$ \\
\hline $\begin{array}{l}\text { Linear max-min } \\
\text { normalization method }\end{array}$ & $r_{i j}=\frac{x_{i j}-x_{j}^{-}}{x_{j}^{+}-x_{j}^{-}}$ & $r_{i j}=\frac{x_{j}^{+}-x_{i j}}{x_{j}^{+}-x_{j}^{-}}$ \\
\hline $\begin{array}{l}\text { Linear normalization } \\
\text { sum-based method }\end{array}$ & $r_{i j}=\frac{x_{i j}}{\sum_{i=1}^{m} x_{i j}}$ & $r_{i j}=\frac{1 / x_{i j}}{\sum_{i=1}^{m} 1 / x_{i j}}$ \\
\hline
\end{tabular}

Note. The notations in Table 2 refer to $r_{i j}$ : the normalized value of the $i$ th alternative on the $j$ th criterion; $x_{i j}$ : the value of the $i$ th alternative on the $j$ th criterion; $\quad x_{j}^{+}=\max _{i} x_{i j} ; \quad x_{j}^{-}=\min _{i} x_{i j} ; \quad \bar{x}_{j}=\sum_{i=1}^{n} x_{i j} / n \quad ;$ $\sigma_{j}=\sqrt{\sum_{i=1}^{n}\left(x_{i j}-\bar{x}_{j}\right)^{2} / n}$.

The linear normalization sum-based method is one of the most widely used normalization methods in classical MCDMs such as the AHP, SWARA and Entropy weighting method (Ahn, 2011). It has the following advantages (Lakshmi \& Venkatesan, 2014): (1) it has less computation time and space complexity; (2) the normalized values reflect the relationships and differences among original evaluation values, simultaneously; (3) the change of original evaluation values has little effect on the dimensionless results. Therefore, we apply the linear normalization sum-based method in this study to transform the three subordinate compromise scores derived by the original CoCoSo method into the numbers in the interval $(0,1)$, so as to eliminate the inconsistency of dimensions.

\section{The Combined Compromise Solution Method with Maximum Variance (MV-CoCoSo)}

\section{Problem Statement}

In the original CoCoSo mehtod, Yazdani et al. (2019b) adopted the hybrid integration operator, i.e., Eq. (9), to synthesize the advantages of the arithmetic average integration operator and geometric average integration operator. However, this integration takes the three subordinate compromise scores, which have great differences in scores, as equally important. For the three subordinate aggregation operators, i.e., Eqs. (6)-(8), it is not difficult to find that $k_{i 1} \in(0,1), k_{i 2}>1$ and $k_{i 3} \in(0,1)$. If we use Eq. (9) to integrate them together, the value of $k_{i 2}$ will have a greater impact on the final result than those of $k_{i 1}$ and $k_{i 3}$, but in practice, $k_{i 2}$ may be the least important among the three subordinate compromise scores. This defect of the original CoCoSo was first pointed out by Wen et al. (2019), and they presented an imporved CoCoSo 
mehtod based on the ORESTE (Wu \& Liao, 2018). However, the improved method is still limited in increasing the discrimination degree among alternatives to improve the recognition of results. To overcome the above limitation, we introduce the operator of "Linear Sum Normalization" to normalize the three subordinate compromise scores to make the aggregated results reasonable.-

In addition, the purpose of MCDM method is to find out the differences among alternatives in terms of the advantages and disadvantages among alternatives. The great discrimination degree of scores regarding evaluation objects is more helpful in supporting decision making. Existing difference-driven comprehensive evaluation methods (Guo, 2012; Li et al., 2018; Ji et al., 2018) mainly depended on the determination of the weight coefficients to connect the original evaluation information and aggregated information. In fact, the calculated evaluation criteria weights can not maximize the overall differences among the evaluated objects, and only under the premise of linear weighting model can widen the difference among the evaluated objects. In this study, we learn from the scatter degree method (Guo, 2012) based on the maximum variance to establish a nonlinear programming model, so that we can aggregate the three subordinate compromise scores in the CoCoSo method and maximize the difference among the aggregated evaluation scores of each evaluation object. In this way, the imporved CoCoSo method not only does not require decision-makers to give specific weights of the subordinate aggregation operators, but also can maximize the global and local differences among alternatives so as to increase the discrimination degree of the evaluation results and avoid the inconsistency ordering, which makes the decision-making process simple and efficient.

\section{The Proposed Method}

An improved CoCoSo method with a new integration function based on the nonlinear programming model with maximum variance is proposed as follows:

Steps 1-4. The same as Steps 1-4 in the original CoCoSo method.

Step 5. Apply the formula of "Linear Sum Normalization", i.e., Eq. (10), to normalize the three subordinate compromise scores:

$$
k_{i h}^{\prime}=k_{i h} / \sum_{i=1}^{m} k_{i h}, \text { for } i=1,2, \cdots, m ; h=1,2,3 .
$$

where $k_{i h}$ is the evaluation score of the $i$ th alternative under the $h$ th aggregation strategy, $k_{i h}^{\prime}$ is the normalized value of $k_{i h}$, such that $k_{i h}^{\prime} \in[0,1]$ and $\sum_{i=1}^{m} k_{i h}^{\prime}=1$.

Step 6. Construct the objective function and its constraints. To make the differences among the evaluated objects as large as possible, the overall difference of the evaluated objects can be measured by the variance of the comprehensive evaluation value of the evaluated objects:

$$
S^{2}=\frac{1}{m} \sum_{i=1}^{m}\left(k_{i}^{\prime \prime}-\bar{k}^{\prime \prime}\right)^{2}
$$

where $k_{i}^{\prime \prime}$ denotes the comprehensive score of each evaluated object after synthesizing the three normalized subordinate compromise scores.
Furthermore, using Eqs. (12) and (13), we can determine the reasonable range of the comprehensive score of each evaluated object:

$$
\begin{gathered}
k_{i}^{\prime \prime} \in\left[k_{i}^{\prime-}, k_{i}^{\prime+}\right] \\
\sum_{i=1}^{m} k_{i}^{\prime \prime}=1
\end{gathered}
$$

where

$$
k_{i}^{\prime-}=\min \left\{k_{i 1}^{\prime}, k_{i 2}^{\prime}, k_{i 3}^{\prime}\right\} \text { and } k_{i}^{\prime+}=\max \left\{k_{i 1}^{\prime}, k_{i 2}^{\prime}, k_{i 3}^{\prime}\right\} \text {. }
$$

According to Eq. (13), the mean of the comprehensive scores of all alternatives can be obtained by:

$$
\bar{k}^{\prime \prime}=\left(k_{1}^{\prime \prime}+k_{2}^{\prime \prime}+\cdots+k_{m}^{\prime \prime}\right) / m=1 / m
$$

According to Eqs. (11) and (14), we can furtherly calculate the variance of comprehensive scores:

$$
S^{2}=\frac{1}{m} \sum_{i=1}^{m}\left(k_{i}^{\prime \prime}-\bar{k}^{\prime \prime}\right)^{2}=\frac{1}{m} \sum_{i=1}^{m}\left(k_{i}^{\prime \prime}-\frac{1}{m}\right)^{2}
$$

Finally, we can construct an objective function and its constraint by synthesizing Eqs. (12)-(15) as following:

$$
\begin{aligned}
& \max \frac{1}{m} \sum_{i=1}^{m}\left(k_{i}^{\prime \prime}-\frac{1}{m}\right)^{2} \\
& \text { s.t. }\left\{\begin{array}{l}
\sum_{i=1}^{m} k_{i}^{\prime \prime}=1 \\
k_{i}^{\prime-} \leq k_{i}^{\prime \prime} \leq k_{i}^{\prime+}
\end{array}\right.
\end{aligned}
$$

Step 7. Rank all the alternatives. The alternative with the maximum $k_{i}^{\prime \prime}$ is chosen as the optimal alternative. The ranking of other available alternatives are determined in descending order of the values of $k_{i}^{\prime \prime}$, for $i=1,2, \cdots, m$.

\section{Case study}

In this section, a case study regarding the trustworthiness determination of CSPs is given, which shows the applicability of the proposed method. First, we briefly describe the background of the case. Second, we apply the proposed method to solve the problem. Finally, we test and validate the proposed method.

\section{Case Description}

Cloud Armor is a research project at the University of Adelaide, which aims to develop a scalable and robust trust management framework for cloud environment. It contains more than 10,000 feedbacks related to QoS criteria, which are provided by nearly 7,000 customers for 114 real-world cloud services. In this study, the sample dataset was extracted from the Cloud Armor project (Noor et al., 2015), which has been used by other scholars (Gireesha et al., 2020; Singh \& Sidhu, 2017; Somu et al., 2017) to validate the accuracy, effectiveness, and feasibility of MCDM methods for CSP selection problem. The dataset consists of the performances of 15 CSPs on 9 QoS criteria. The benchmark criteria include: availability $\left(\mathrm{A}_{\mathrm{v}}\right)$, response time $\left(\mathrm{R}_{\mathrm{t}}\right)$, price $\left(\mathrm{P}_{\mathrm{r}}\right)$, speed $\left(\mathrm{S}_{\mathrm{p}}\right)$, storage space $\left(\mathrm{S}_{\mathrm{s}}\right)$, features $\left(\mathrm{F}_{\mathrm{e}}\right)$, ease of use $\left(E_{u}\right)$, technical support $\left(T_{s}\right)$ and customer service $\left(C_{s}\right)$. All the criteria are assumed as beneficial criteria, and a fivepoint scale was used for the criteria in which the value " 1 " indicates the most insignificant feedback score while the value " 5 " indicates the most significant feedback score. In addition, the relative normalized weights of the QoS criteria are as follows: $\mathrm{A}_{\mathrm{v}}=0.1212, \mathrm{R}_{\mathrm{t}}=0.1364, \mathrm{P}_{\mathrm{r}}=0.1364, \mathrm{~S}_{\mathrm{p}}=$ 
Han Lai, Huchang Liao, Zhi Wen, Edmundas Kazimieras Zavadskas, Abdullah Al-Barakati. An Improved CoCoSo Method...

$0.1061, \mathrm{~S}_{\mathrm{s}}=0.1061, \mathrm{~F}_{\mathrm{e}}=0.0909, \mathrm{E}_{\mathrm{u}}=0.0909, \mathrm{~T}_{\mathrm{s}}=0.1061$, and $\mathrm{C}_{\mathrm{s}}=0.1061$.

\section{Applying the MV-CoCoSo Method to Solve the Case}

Step 1. From the dataset (Noor et al., 2015), a decision matrix with respect to 15 CSPs on 9 QoS criteria is obtained as shown in Table 3. Then, we normalize the initial decision matrix by Eq. (2), and the results are shown in Table 4.

Combined with the weight of each criteria, we can calculate the sum of the weighted comparability sequences and power-weighted comparability sequences by Eqs. (4) and (5), respectively. The vector of the sum of weighted comparability sequences for each CSP $S$ and the powerweighted comparability sequences for each CSP $P$ can be obtained as: $S=(0.9472,0.9383,0.3473,0.7590,0.9648$, 1.0002, 0.7312, 0.9472, 0.6037, 0.4117, 0.2437, 0.9017, 0.3473, $0.9547,0.8891)^{T}, \quad P=(8.9291,8.9278,6.3141,8.6797,8.9579$, 9.0000, 8.6757, 8.9399, 8.4631, 4.7777, 5.4553, 8.8861, 6.4082, $8.9462,8.8679)^{T}$. Then, the three subordinate compromise scores are obtained by Eqs. (6)-(8). The results are shown in Table 5. Here we let $\lambda=0.5$ in Eq. (8).

Table 3

The Decision Matrix with Respect to 15 CSPs on 9 QoS Criteria

\begin{tabular}{|c|c|c|c|c|c|c|c|c|c|}
\hline CSP & $\mathbf{A}_{\mathbf{v}}$ & $\mathbf{R}_{\mathbf{t}}$ & $\mathbf{P}_{\mathbf{r}}$ & $S_{p}$ & $\mathbf{S}_{\mathrm{s}}$ & $\mathbf{F}_{\mathrm{e}}$ & $\mathbf{E}_{\mathbf{u}}$ & $\mathbf{T}_{\mathrm{s}}$ & $\mathrm{C}_{\mathrm{s}}$ \\
\hline CSP01 & 5 & 5 & 5 & 3 & 5 & 5 & 5 & 5 & 5 \\
\hline CSP02 & 5 & 5 & 5 & 4 & 4 & 5 & 5 & 5 & 5 \\
\hline CSP03 & 3 & 3 & 3 & 4 & 5 & 2 & 2 & 2 & 2 \\
\hline CSP04 & 5 & 4 & 4 & 4 & 3 & 4 & 5 & 5 & 5 \\
\hline CSP05 & 5 & 5 & 5 & 5 & 4 & 5 & 5 & 5 & 5 \\
\hline CSP06 & 5 & 5 & 5 & 5 & 5 & 5 & 5 & 5 & 5 \\
\hline CSP07 & 4 & 4 & 4 & 4 & 4 & 5 & 5 & 4 & 4 \\
\hline CSP08 & 5 & 5 & 5 & 5 & 5 & 5 & 5 & 4 & 4 \\
\hline CSP09 & 3 & 4 & 4 & 3 & 4 & 3 & 5 & 4 & 4 \\
\hline CSP10 & 5 & 4 & 4 & 1 & 4 & 4 & 1 & 1 & 1 \\
\hline CSP11 & 2 & 3 & 2 & 3 & 3 & 3 & 3 & 2 & 3 \\
\hline CSP12 & 5 & 5 & 4 & 5 & 5 & 5 & 5 & 4 & 4 \\
\hline CSP13 & 3 & 3 & 3 & 3 & 2 & 3 & 3 & 4 & 3 \\
\hline CSP14 & 5 & 5 & 4 & 5 & 5 & 5 & 5 & 5 & 5 \\
\hline CSP15 & 5 & 5 & 4 & 5 & 4 & 4 & 5 & 5 & 5 \\
\hline
\end{tabular}

Step 2. After obtained the results of three subordinate aggregation operators, the three subordinate compromise scores $k_{i 1}, k_{i 2}$ and $k_{i 3}$ are normalized using Eq. (10).

Step 3. We construct objective function and its constraints based on Eq. (16). By LINGO 17.0 software package, we can produce the comprehensive score of each CSP $k_{i}^{\prime \prime}$. The final ranks can be gained accordingly as shown in Table 6. From Table 6, it is evident that CSP06 $\left(k_{i}^{\prime \prime}=0.0852\right)$ is determined to be the most trustworthy service provider. In contrast, CSP11 $\left(k_{i}^{\prime \prime}=0.0305\right)$ is determined to be the least trustworthy service provider.

\section{Test and Validation of the Proposed Method}

In this section, the performances of the MV-CoCoSo method are tested and validated from three aspects: sensitivity analysis, results consistency comparison, and discrimination test.

Table 4

The Normalized Decision Matrix

\begin{tabular}{|c|c|c|c|c|c|c|c|c|c|}
\hline $\mathbf{C S P}$ & $\mathbf{A}_{\mathbf{v}}$ & $\mathbf{R}_{\mathbf{t}}$ & $\mathbf{P}_{\mathbf{r}}$ & $\mathbf{S}_{\mathbf{p}}$ & $\mathbf{S}_{\mathbf{s}}$ & $\mathbf{F}_{\mathbf{e}}$ & $\mathbf{E}_{\mathbf{u}}$ & $\mathbf{T}_{\mathbf{s}}$ & $\mathbf{C}_{\mathbf{s}}$ \\
\hline CSP01 & 1.0000 & 1.0000 & 1.0000 & 0.5000 & 1.0000 & 1.0000 & 1.0000 & 1.0000 & 1.0000 \\
\hline CSP02 & 1.0000 & 1.0000 & 1.0000 & 0.7500 & 0.6667 & 1.0000 & 1.0000 & 1.0000 & 1.0000 \\
\hline CSP03 & 0.3333 & 0.0000 & 0.3333 & 0.7500 & 1.0000 & 0.0000 & 0.2500 & 0.2500 & 0.2500 \\
\hline CSP04 & 1.0000 & 0.5000 & 0.6667 & 0.7500 & 0.3333 & 0.6667 & 1.0000 & 1.0000 & 1.0000 \\
\hline CSP05 & 1.0000 & 1.0000 & 1.0000 & 1.0000 & 0.6667 & 1.0000 & 1.0000 & 1.0000 & 1.0000 \\
\hline CSP06 & 1.0000 & 1.0000 & 1.0000 & 1.0000 & 1.0000 & 1.0000 & 1.0000 & 1.0000 & 1.0000 \\
\hline CSP07 & 0.6667 & 0.5000 & 0.6667 & 0.7500 & 0.6667 & 1.0000 & 1.0000 & 0.7500 & 0.7500 \\
\hline CSP08 & 1.0000 & 1.0000 & 1.0000 & 1.0000 & 1.0000 & 1.0000 & 1.0000 & 0.7500 & 0.7500 \\
\hline CSP09 & 0.3333 & 0.5000 & 0.6667 & 0.5000 & 0.6667 & 0.3333 & 1.0000 & 0.7500 & 0.7500 \\
\hline CSP10 & 1.0000 & 0.5000 & 0.6667 & 0.0000 & 0.6667 & 0.6667 & 0.0000 & 0.0000 & 0.0000 \\
\hline CSP11 & 0.0000 & 0.0000 & 0.0000 & 0.5000 & 0.3333 & 0.3333 & 0.5000 & 0.2500 & 0.5000 \\
\hline CSP12 & 1.0000 & 1.0000 & 0.6667 & 1.0000 & 1.0000 & 1.0000 & 1.0000 & 0.7500 & 0.7500 \\
\hline CSP13 & 0.3333 & 0.0000 & 0.3333 & 0.5000 & 0.0000 & 0.3333 & 0.5000 & 0.7500 & 0.5000 \\
\hline CSP14 & 1.0000 & 1.0000 & 0.6667 & 1.0000 & 1.0000 & 1.0000 & 1.0000 & 1.0000 & 1.0000 \\
\hline CSP15 & 1.0000 & 1.0000 & 0.6667 & 1.0000 & 0.6667 & 0.6667 & 1.0000 & 1.0000 & 1.0000 \\
\hline
\end{tabular}

The Results of three Subordinate Aggregation Operators

Table 5

\begin{tabular}{|c|c|c|c|c|c|c|}
\hline CSP & $k_{i 1}$ & Rank & $k_{i 2}$ & Rank & $k_{i 3}$ & Rank \\
\hline CSP01 & 0.0753 & 4 & 5.7548 & 5 & 0.9876 & 5 \\
\hline CSP02 & 0.0752 & 6 & 5.7183 & 6 & 0.9866 & 6 \\
\hline CSP03 & 0.0508 & 13 & 2.7465 & 13 & 0.6661 & 13 \\
\hline CSP04 & 0.0719 & 9 & 4.9306 & 9 & 0.9438 & 9 \\
\hline CSP05 & 0.0756 & 2 & 5.8334 & 2 & 0.9923 & 2 \\
\hline
\end{tabular}




\begin{tabular}{|c|c|c|c|c|c|c|}
\hline CSP & $k_{i 1}$ & Rank & $k_{i 2}$ & Rank & $k_{i 3}$ & Rank \\
\hline CSP06 & 0.0762 & 1 & 5.9873 & 1 & 1.0000 & 1 \\
\hline CSP07 & 0.0717 & 10 & 4.8157 & 10 & 0.9407 & 10 \\
\hline CSP08 & 0.0753 & 5 & 5.7570 & 4 & 0.9887 & 4 \\
\hline CSP09 & 0.0691 & 11 & 4.2481 & 11 & 0.9067 & 11 \\
\hline CSP10 & 0.0395 & 15 & 2.6889 & 14 & 0.5189 & 15 \\
\hline CSP11 & 0.0434 & 14 & 2.1418 & 15 & 0.5699 & 14 \\
\hline CSP12 & 0.0746 & 7 & 5.5593 & 7 & 0.9788 & 7 \\
\hline CSP13 & 0.0515 & 12 & 2.7661 & 12 & 0.6755 & 12 \\
\hline CSP14 & 0.0755 & 3 & 5.7895 & 3 & 0.9901 & 3 \\
\hline CSP15 & 0.0744 & 8 & 5.5037 & 8 & 0.9757 & 8 \\
\hline
\end{tabular}

Table 6

The Final Aggregation Ranking of the CSPs

\begin{tabular}{|c|c|c|c|c|c|}
\hline CSP & $k_{i 1}^{\prime}$ & $k_{i 2}^{\prime}$ & $k_{i 3}^{\prime}$ & $k_{i}^{\prime \prime}$ & Rank \\
\hline CSP01 & 0.0753 & 0.0819 & 0.0753 & 0.0819 & 5 \\
\hline CSP02 & 0.0752 & 0.0814 & 0.0752 & 0.0814 & 6 \\
\hline CSP03 & 0.0508 & 0.0391 & 0.0508 & 0.0391 & 13 \\
\hline CSP04 & 0.0719 & 0.0702 & 0.0719 & 0.0702 & 9 \\
\hline CSP05 & 0.0756 & 0.0830 & 0.0756 & 0.0830 & 2 \\
\hline CSP06 & 0.0762 & 0.0852 & 0.0762 & 0.0852 & 1 \\
\hline CSP07 & 0.0717 & 0.0686 & 0.0717 & 0.0686 & 10 \\
\hline CSP08 & 0.0753 & 0.0820 & 0.0753 & 0.0820 & 4 \\
\hline CSP10 & 0.0691 & 0.0605 & 0.0691 & 0.0605 & 11 \\
\hline CSP11 & 0.0395 & 0.0383 & 0.0395 & 0.0383 & 14 \\
\hline CSP12 & 0.0434 & 0.0305 & 0.0434 & 0.0305 & 15 \\
\hline CSP13 & 0.0746 & 0.0791 & 0.0746 & 0.0791 & 7 \\
\hline CSP15 & 0.0515 & 0.0394 & 0.0515 & 0.0394 & \\
\hline
\end{tabular}

\section{Sensitivity Analysis}

We perform sensitivity analysis to validate the results and justify the accuracy and deviation of the decision outcomes derived by the proposed method. The sensitivity analysis can help decision-makers understand the robustness of the method by changing the data. Here, we perform two sensitivity tests.

First, we adopt the weight replacement strategy for sensitivity test. Since some criteria have the same weight, we exclude the case that the weights of criteria are still the same after the exchange. Finally, there are 28 different experiments being conducted. The weight information of each criterion in each experiment is shown in Table 7. For each experiment, the $k_{i}^{\prime \prime} \quad$ values are obtained and a different name is given to each calculation. For example, $A_{v}-R_{t}$ denotes that the weights of criterion $A_{v}$ and criterion $R_{t}$ are interchanged. Figure 1 shows the results of the experiment of sensitivity analysis on the criteria weights. From Figure 1, it is clear that CSP06 ranks the first and CSP11 ranks the last in all experiments, and the second-best CSP is CSP05 in the 25 experiments out of 28 experiments. As a whole, there are few deviations in other CSPs. Therefore, for the obtained results, it is obvious that our decision-making model is robust and rarely sensitive to the criteria weights. In addition, according to Eq. 8 (in Step 4) in the proposed algorithm, we can find that the effect of eventual ranking can be related to $\lambda$. Therefore, we perform a sensitivity analysis based on the change of the value of $\lambda$ in the range from 0 to 1 . From Table 8 , it is clearly seen that for the change of $\lambda$ value, there is no change in the final ranking obtained by the proposed method throughout the analysis. Therefore, it can be concluded that the final ranking results are reliable and robust based on the sensitivity analysis.

\section{The Consistency Comparison of Ranking Results}

Based on the ranking results, we also compare the proposed method with other MCDM methods, involving the WASPAS (Zavadskas et al., 2012), VIKOR (Opricovic, 1998), TOPSIS (Ginting et al., 2017), CODAS (Keshavarz Ghorabaee et al., 2016), and the original CoCoSo method (Yazdani et al., 2019b), as shown in Table 9.

From Table 9, we can find that the results obtained by the proposed approach have high degrees of similarity with those deduced by other MCDM methods. In particular, the top three alternatives selected by the proposed method are completely consistent with other MCDM methods. In addition, we adopt the Spearman's rank correlation coefficients (Liao \& Wu, 2020) to compare the ranking results obtained by different techniques. The correlation coefficient ( $C C$ ) is between -1 and 1 . The larger value indicates the stronger correspondence of the compared rankings. If $C C \geq 0.8$, the relationship between variables is considered high. In this regard, the proposed method is in a significant consistent with the other five applied methods (Table 10). We can see that all the Spearman's rho correlation coefficient values are significant at the 0.01 level of significance. Especially, we can find that the lowest correlation coefficient ( ) of the proposed method is higher than that of other methods from the bold part of Table 10 (expect for the original CoCoSo method, because the proposed method and the original CoCoSo method have the same ranking result). Meanwhile, the average correlation coefficient ( ) of each method also be calculated as follows: $==0.987,=0.977,=0.978,=0.982,=0.981$. These results imply a high reliability of our method. 
Han Lai, Huchang Liao, Zhi Wen, Edmundas Kazimieras Zavadskas, Abdullah Al-Barakati. An Improved CoCoSo Method...

Table 7

Experiments for Weight Sensitivity Analysis

\begin{tabular}{|c|c|c|c|c|c|c|c|c|c|c|}
\hline & Definition & $\mathbf{A}_{\mathbf{v}}$ & $\mathbf{R}_{t}$ & $\mathbf{P}_{\mathbf{r}}$ & $S_{p}$ & $\mathbf{S}_{\mathrm{s}}$ & $F_{e}$ & $\mathbf{E}_{\mathbf{u}}$ & $\mathbf{T}_{\mathrm{s}}$ & $\mathrm{C}_{\mathrm{s}}$ \\
\hline $\mathrm{T} 1$ & $A_{v}-R_{t}$ & 0.1364 & 0.1212 & 0.1364 & 0.1061 & 0.1061 & 0.0909 & 0.0909 & 0.1061 & 0.1061 \\
\hline $\mathrm{T} 2$ & $\mathrm{~A}_{\mathrm{V}}-\mathrm{P}_{\mathrm{r}}$ & 0.1364 & 0.1364 & 0.1212 & 0.1061 & 0.1061 & 0.0909 & 0.0909 & 0.1061 & 0.1061 \\
\hline T3 & $A_{v}-S_{p}$ & 0.1061 & 0.1364 & 0.1364 & 0.1212 & 0.1061 & 0.0909 & 0.0909 & 0.1061 & 0.1061 \\
\hline $\mathrm{T} 4$ & $A_{v}-S_{s}$ & 0.1061 & 0.1364 & 0.1364 & 0.1061 & 0.1212 & 0.0909 & 0.0909 & 0.1061 & 0.1061 \\
\hline T5 & $\mathrm{A}_{\mathrm{V}}-\mathrm{F}_{\mathrm{e}}$ & 0.0909 & 0.1364 & 0.1364 & 0.1061 & 0.1061 & 0.1212 & 0.0909 & 0.1061 & 0.1061 \\
\hline T6 & $A_{v}-E_{u}$ & 0.0909 & 0.1364 & 0.1364 & 0.1061 & 0.1061 & 0.0909 & 0.1212 & 0.1061 & 0.1061 \\
\hline $\mathrm{T} 7$ & $\mathrm{~A}_{\mathrm{V}}-\mathrm{T}_{\mathrm{s}}$ & 0.1061 & 0.1364 & 0.1364 & 0.1061 & 0.1061 & 0.0909 & 0.0909 & 0.1212 & 0.1061 \\
\hline $\mathrm{T} 8$ & $\mathrm{~A}_{\mathrm{v}}-\mathrm{C}_{\mathrm{s}}$ & 0.1061 & 0.1364 & 0.1364 & 0.1061 & 0.1061 & 0.0909 & 0.0909 & 0.1061 & 0.1212 \\
\hline T9 & $\mathrm{R}_{\mathrm{t}}-\mathrm{S}_{\mathrm{p}}$ & 0.1212 & 0.1061 & 0.1364 & 0.1364 & 0.1061 & 0.0909 & 0.0909 & 0.1061 & 0.1061 \\
\hline T10 & $\mathrm{R}_{\mathrm{t}}-\mathrm{S}_{\mathrm{s}}$ & 0.1212 & 0.1061 & 0.1364 & 0.1061 & 0.1364 & 0.0909 & 0.0909 & 0.1061 & 0.1061 \\
\hline T11 & $\mathrm{R}_{\mathrm{t}}-\mathrm{F}_{\mathrm{e}}$ & 0.1212 & 0.0909 & 0.1364 & 0.1061 & 0.1061 & 0.1364 & 0.0909 & 0.1061 & 0.1061 \\
\hline T12 & $\mathrm{R}_{\mathrm{t}}-\mathrm{E}_{\mathrm{u}}$ & 0.1212 & 0.0909 & 0.1364 & 0.1061 & 0.1061 & 0.0909 & 0.1364 & 0.1061 & 0.1061 \\
\hline T13 & $\mathrm{R}_{\mathrm{t}}-\mathrm{T}_{\mathrm{s}}$ & 0.1212 & 0.1061 & 0.1364 & 0.1061 & 0.1061 & 0.0909 & 0.0909 & 0.1364 & 0.1061 \\
\hline T14 & $\mathrm{R}_{\mathrm{t}}-\mathrm{C}_{\mathrm{s}}$ & 0.1212 & 0.1061 & 0.1364 & 0.1061 & 0.1061 & 0.0909 & 0.0909 & 0.1061 & 0.1364 \\
\hline T15 & $P_{r}-S_{p}$ & 0.1212 & 0.1364 & 0.1061 & 0.1364 & 0.1061 & 0.0909 & 0.0909 & 0.1061 & 0.1061 \\
\hline T16 & $\mathrm{P}_{\mathrm{r}}-\mathrm{S}_{\mathrm{S}}$ & 0.1212 & 0.1364 & 0.1061 & 0.1061 & 0.1364 & 0.0909 & 0.0909 & 0.1061 & 0.1061 \\
\hline T17 & $\mathrm{P}_{\mathrm{r}}-\mathrm{F}_{\mathrm{e}}$ & 0.1212 & 0.1364 & 0.0909 & 0.1061 & 0.1061 & 0.1364 & 0.0909 & 0.1061 & 0.1061 \\
\hline T18 & $P_{r}-E_{u}$ & 0.1212 & 0.1364 & 0.0909 & 0.1061 & 0.1061 & 0.0909 & 0.1364 & 0.1061 & 0.1061 \\
\hline T19 & $\mathrm{P}_{\mathrm{r}}-\mathrm{T}_{\mathrm{S}}$ & 0.1212 & 0.1364 & 0.1061 & 0.1061 & 0.1061 & 0.0909 & 0.0909 & 0.1364 & 0.1061 \\
\hline T20 & $\mathrm{P}_{\mathrm{r}}-\mathrm{C}_{\mathrm{s}}$ & 0.1212 & 0.1364 & 0.1061 & 0.1061 & 0.1061 & 0.0909 & 0.0909 & 0.1061 & 0.1364 \\
\hline T21 & $\mathrm{S}_{\mathrm{p}}-\mathrm{F}_{\mathrm{e}}$ & 0.1212 & 0.1364 & 0.1364 & 0.0909 & 0.1061 & 0.1061 & 0.0909 & 0.1061 & 0.1061 \\
\hline T22 & $S_{p}-E_{u}$ & 0.1212 & 0.1364 & 0.1364 & 0.0909 & 0.1061 & 0.0909 & 0.1061 & 0.1061 & 0.1061 \\
\hline T23 & $\mathrm{S}_{\mathrm{s}}-\mathrm{F}_{\mathrm{e}}$ & 0.1212 & 0.1364 & 0.1364 & 0.1061 & 0.0909 & 0.1061 & 0.0909 & 0.1061 & 0.1061 \\
\hline T24 & $\mathrm{S}_{\mathrm{s}}-\mathrm{E}_{\mathrm{u}}$ & 0.1212 & 0.1364 & 0.1364 & 0.1061 & 0.0909 & 0.0909 & 0.1061 & 0.1061 & 0.1061 \\
\hline T25 & $\mathrm{F}_{\mathrm{e}}-\mathrm{T}_{\mathrm{s}}$ & 0.1212 & 0.1364 & 0.1364 & 0.1061 & 0.1061 & 0.1061 & 0.0909 & 0.0909 & 0.1061 \\
\hline T26 & $\mathrm{F}_{\mathrm{e}}-\mathrm{C}_{\mathrm{s}}$ & 0.1212 & 0.1364 & 0.1364 & 0.1061 & 0.1061 & 0.1061 & 0.0909 & 0.1061 & 0.0909 \\
\hline T27 & $\mathrm{E}_{\mathrm{u}}-\mathrm{T}_{\mathrm{s}}$ & 0.1212 & 0.1364 & 0.1364 & 0.1061 & 0.1061 & 0.0909 & 0.1061 & 0.0909 & 0.1061 \\
\hline T28 & $\mathrm{E}_{\mathrm{u}}-\mathrm{C}_{\mathrm{s}}$ & 0.1212 & 0.1364 & 0.1364 & 0.1061 & 0.1061 & 0.0909 & 0.1061 & 0.1061 & 0.0909 \\
\hline
\end{tabular}

Table 8

The Experiment Results of Sensitivity Analysis of the Parameter $\lambda$

\begin{tabular}{|c|c|c|c|c|c|c|c|c|c|c|c|}
\hline CSP & $\lambda=0$ & $\lambda=0.1$ & $\lambda=0.2$ & $\lambda=0.3$ & $\lambda=0.4$ & $\lambda=0.5$ & $\lambda=0.6$ & $\lambda=0.7$ & $\lambda=0.8$ & $\lambda=0.9$ & $\lambda=1$ \\
\hline CSP01 & 5 & 5 & 5 & 5 & 5 & 5 & 5 & 5 & 5 & 5 & 5 \\
\hline CSP02 & 6 & 6 & 6 & 6 & 6 & 6 & 6 & 6 & 6 & 6 & 6 \\
\hline CSP03 & 13 & 13 & 13 & 13 & 13 & 13 & 13 & 13 & 13 & 13 & 13 \\
\hline CSP04 & 9 & 9 & 9 & 9 & 9 & 9 & 9 & 9 & 9 & 9 & 9 \\
\hline CSP05 & 2 & 2 & 2 & 2 & 2 & 2 & 2 & 2 & 2 & 2 & 2 \\
\hline CSP06 & 1 & 1 & 1 & 1 & 1 & 1 & 1 & 1 & 1 & 1 & 1 \\
\hline CSP07 & 10 & 10 & 10 & 10 & 10 & 10 & 10 & 10 & 10 & 10 & 10 \\
\hline CSP08 & 4 & 4 & 4 & 4 & 4 & 4 & 4 & 4 & 4 & 4 & 4 \\
\hline CSP09 & 11 & 11 & 11 & 11 & 11 & 11 & 11 & 11 & 11 & 11 & 11 \\
\hline CSP10 & 14 & 14 & 14 & 14 & 14 & 14 & 14 & 14 & 14 & 14 & 14 \\
\hline CSP11 & 15 & 15 & 15 & 15 & 15 & 15 & 15 & 15 & 15 & 15 & 15 \\
\hline CSP12 & 7 & 7 & 7 & 7 & 7 & 7 & 7 & 7 & 7 & 7 & 7 \\
\hline CSP13 & 12 & 12 & 12 & 12 & 12 & 12 & 12 & 12 & 12 & 12 & 12 \\
\hline CSP14 & 3 & 3 & 3 & 3 & 3 & 3 & 3 & 3 & 3 & 3 & 3 \\
\hline CSP15 & 8 & 8 & 8 & 8 & 8 & 8 & 8 & 8 & 8 & 8 & 8 \\
\hline
\end{tabular}

\section{Discrimination Test}

Decision-makers evaluate an alternative by various methods, mainly relying on the final scores of alternatives. If there is a large gap among the scores of different alternatives, it is easy to determine the ranking of alternatives. Otherwise, it is somewhat difficult to rank when the gap among these scores is small. In this sense, we perform a discrimination test to verify the discrimination degree of the proposed methods from the local and global points of view.

Table 9

The Ranking Comparison between the Proposed Method and other MCDM Methods

\begin{tabular}{|c|c|c|c|c|c|c|}
\hline CSP & MV-CoCoSo & CoCoSo & TOPSIS & VIKOR & WASPAS & CODAS \\
\hline CSP01 & 5 & 5 & 8 & 5 & 6 & 5 \\
\hline CSP02 & 6 & 6 & 5 & 6 & 4 & 4 \\
\hline CSP03 & 13 & 13 & 13 & 13 & 13 & 14 \\
\hline CSP04 & 9 & 9 & 9 & 9 & 9 & 9 \\
\hline CSP05 & 2 & 2 & 2 & 2 & 2 & 2 \\
\hline CSP06 & 1 & 1 & 1 & 1 & 1 & 1 \\
\hline CSP07 & 10 & 10 & 10 & 10 & 10 & 10 \\
\hline CSP08 & 4 & 4 & 4 & 4 & 5 & 6 \\
\hline CSP09 & 11 & 11 & 11 & 11 & 11 & 11 \\
\hline
\end{tabular}




\begin{tabular}{|c|c|c|c|c|c|c|}
\hline CSP & MV-CoCoSo & CoCoSo & TOPSIS & VIKOR & WASPAS & CODAS \\
\hline CSP10 & 14 & 14 & 14 & 12 & 15 & 13 \\
\hline CSP11 & 15 & 15 & 15 & 15 & 14 & 15 \\
\hline CSP12 & 7 & 7 & 7 & 7 & 8 & 12 \\
\hline CSP13 & 12 & 12 & 12 & 14 & 3 & 12 \\
\hline CSP14 & 3 & 3 & 3 & 3 & 3 & 7 \\
\hline CSP15 & 8 & 8 & 6 & 8 & & 7 \\
\hline
\end{tabular}

Numerical Results of Spearman's Rho Test of Correlation Significance of Ranks between the Compared Methods

\begin{tabular}{|c|c|c|c|c|c|c|c|}
\hline \multicolumn{2}{|c|}{ Spearman's rho } & MV-CoCoSo & CoCoSo & TOPSIS & VIKOR & WASPAS & CODAS \\
\hline MV-CoCoSo & $\begin{array}{l}\text { Correlation } \\
\text { Coefficient }\end{array}$ & 1.000 & $1.000^{* *}$ & $.975^{* *}$ & $.986^{* *}$ & $.982^{* *}$ & $.979^{* *}$ \\
\hline CoCoSo & $\begin{array}{l}\text { Correlation } \\
\text { Coefficient }\end{array}$ & $1.000^{* *}$ & 1.000 & $.975^{* *}$ & $.986^{* *}$ & $.982^{* *}$ & $.979^{* *}$ \\
\hline TOPSIS & $\begin{array}{l}\text { Correlation } \\
\text { Coefficient }\end{array}$ & $.975^{* *}$ & $.975^{* *}$ & 1.000 & $.961^{* *}$ & $.982^{* *}$ & $.968^{* *}$ \\
\hline VIKOR & $\begin{array}{l}\text { Correlation } \\
\text { Coefficient }\end{array}$ & $.986^{* *}$ & $.986^{* *}$ & $.961^{* *}$ & 1.000 & $.961^{* *}$ & $.971^{* *}$ \\
\hline WASPAS & $\begin{array}{l}\text { Correlation } \\
\text { Coefficient }\end{array}$ & $.982^{* *}$ & $.982^{* *}$ & $.982^{* *}$ & $.961^{* *}$ & 1.000 & $.986^{* *}$ \\
\hline CODAS & $\begin{array}{l}\text { Correlation } \\
\text { Coefficient }\end{array}$ & $.979^{* *}$ & $.979^{* *}$ & $.968^{* *}$ & $.971^{* *}$ & $.986^{* *}$ & 1.000 \\
\hline
\end{tabular}

Note: ** denotes the correlation was significant at 0.01 level (double tail).

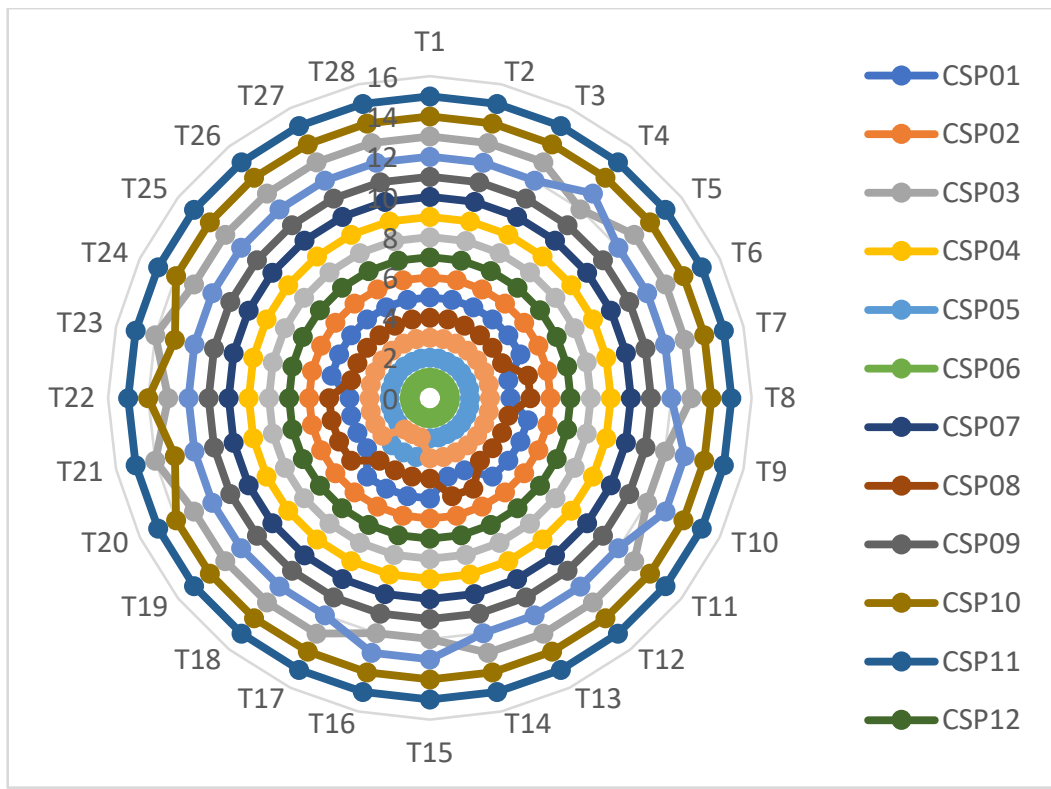

Figure 1. Results of the Sensitivity Analysis on the Criteria Weights

To test the local discrimination degree, we compare the proposed method with the original CoCoSo method by Eq. (17), which uses the relative deviation (Ke et al., 2007) to demonstrate the improvement of the proposed method in terms of the discrimination degree:

$$
\eta=\frac{\alpha_{\max }-\alpha_{\mathrm{sec}}}{\alpha_{\max }} \times 100 \%
$$

where $\alpha_{\max }$ and $\alpha_{\mathrm{sec}}$ denote the final scores of the alternatives that rank at the first preferred position and the second preferred position. $\eta$ denotes the relative deviation between the first preferred alternative and the second preferred alternative. The higher $\eta$ is, the better the method is in discrimination.

Suppose that $A_{i}(i=1,2, \cdots, m)$ are alternatives, $D_{t}$ $(t=1,2, \cdots, q)$ are decision-making methods, the values for the alternatives obtained by different methods are $H_{i t}$ $(i=1, \cdots, m ; t=1, \cdots, q)$. To test the global discrimination degree of each method, the discrimination ability index $Q_{t}$ could be built as (Ma, 2019):

$$
\begin{aligned}
& \mu_{t}=\frac{1}{m} \sum_{i=1}^{m} H_{i t}, t=1,2, \cdots, q \\
& \lambda_{t}=\sum_{i<j}\left|H_{i t}-H_{j t}\right|, t=1,2, \cdots, q \\
& Q_{t}=\frac{\lambda_{t}}{\mu_{t}},(t=1,2, \cdots, q)
\end{aligned}
$$

where $Q_{t}$ reflects the discrimination ability of alternative $A_{i}$ ranked by $D_{t}$. The higher $Q$ is, the better the method is in discrimination. 
Table 11

The Dataset of a Logistic Provider Selection in the Original CoCoSo Method (Yazdani et al., 2019)

\begin{tabular}{|c|c|c|c|c|c|}
\hline & \multicolumn{5}{|c|}{ Criteria } \\
\hline Alternatives & C1 & C2 & C3 & C4 & C5 \\
\hline Criteria type & Benefit & Cost & Benefit & Benefit & Benefit \\
\hline Weights & 0.036 & 0.192 & 0.326 & 0.326 & 0.12 \\
\hline A1 & 60 & 0.4 & 2,540 & 500 & 990 \\
\hline A2 & 6.35 & 0.15 & 1,016 & 3,000 & 1,041 \\
\hline A3 & 6.8 & 0.1 & $1,727.2$ & 1,500 & 1,676 \\
\hline A4 & 10 & 0.2 & 1,000 & 2,000 & 965 \\
\hline A5 & 2.5 & 0.1 & 560 & 500 & 915 \\
\hline A6 & 4.5 & 0.08 & 1,016 & 350 & 508 \\
\hline A7 & 3 & 0.1 & 1,778 & 1,000 & 920 \\
\hline
\end{tabular}

By Eq. (17), we can obtain that the $\eta$ of the proposed method is $2.58 \%$, while the $\eta$ of the original CoCoSo method is $2.07 \%$ in this case study. In addition, by Eq. (18)(20), we can obtain that the $Q$ of the proposed method is 37.83, while the $Q$ of the original CoCoSo method is 30.24. Thus, we can conclude that, compared with the original CoCoSo method, the proposed method is easier to make final decision.

We also use the dataset associated with the original CoCoSo method (Yazdani et al., 2019) to validate the performance of the proposed algorithm. The dataset was related to a logistic provider selection problem, as displayed in Table 11.

Table 12 gives the final scores and ranks of each alternative derived by the proposed method and the original CoCoSo method. From Table 12, we can find that the proposed method has the same ranking results as those derived by the original CoCoSo method. However, the $\eta$ of the proposed method is $3.66 \%$, while the $\eta$ of the original CoCoSo method is $3.26 \%$; the $Q$ of the proposed method is 6.07 , while the $Q$ of the original CoCoSo method is 5.75 . Hence, it can be concluded that the discrimination ability of alternatives ranking of the proposed method is superior to the original CoCoSo method from the local and global perspectives.

\section{Conclusions}

In this study, we proposed an improved CoCoSo method for the CSP selection. The final aggregation operator in the original CoCoSo method takes the equal importance of the three subordinate compromise scores. To avoid this defect, we introduced the "Linear Sum Normalization" to normalize the three subordinate compromise scores so as to make the aggregated results reasonable. In addition, we introduced a nonlinear programming model with variance maximization to aggregate the three subordinate compromise scores and maximize the divergence among the aggregated scores of each evaluation object. The proposed method can avoid contradictory and increase the discrimination degree of evaluation results, so as to help decision-makers select the optimal CSP. To prove the advantages of the proposed method, a numerical example of the trust evaluation of CSPs was conducted based on the synthetic and real cloud data derived from the Cloud Armor project. By sensitive analysis, the stability of the proposed model was approved. The ranking results was highly consistent with those deduced by other existing decision-making methods. Furthermore, the results of discrimination test also indicated that the proposed method is more effective than the original CoCoSo method to identify the subtle difference among alternatives.

Our future work will focus on extending this algorithm by Z-numbers and D-numbers to support MCDM for handling information reliability problems involved in the decision-making process and enhance evidential reasoning ability for increasing the accuracy of CSP selection. In addition, we intend to further optimize our approach and explore its applicability in renewable energy investment and green economy development. Since the essence of a green economy is the sustainable development of the economy with the coordinated development of both ecology and economy, it needs to consider multiple conflicting criteria, which will lead to inaccessibility of utopia alternatives.

\section{The Ranking Results of MV-CoCoSo and Original CoCoSo Method}

\begin{tabular}{|c|c|c|c|c|c|c|c|}
\hline \multirow{2}{*}{ Alternatives } & \multirow{2}{*}{$k_{i 1}$} & \multirow{2}{*}{$k_{i 2}$} & \multirow{2}{*}{$k_{i 3}$} & \multicolumn{2}{|c|}{ CoCoSo } & \multicolumn{2}{|c|}{ MV-CoCoSo } \\
\cline { 5 - 8 } & & & & $k_{i}$ & Rank & $k_{i}^{\prime \prime}$ & \multicolumn{2}{c|}{ Rank } \\
\hline A1 & 0.131 & 3.245 & 0.724 & 2.041 & 5 & 0.131 & 5 \\
\hline A2 & 0.175 & 4.473 & 0.973 & 2.788 & 2 & 0.184 & 2 \\
\hline A3 & 0.18 & 4.64 & 1 & 2.882 & 1 & 0.191 & 1 \\
\hline A4 & 0.163 & 3.721 & 0.906 & 2.416 & 4 & 0.154 & 4 \\
\hline A5 & 0.088 & 2 & 0.487 & 1.299 & 7 & 0.082 & 7 \\
\hline A6 & 0.097 & 2.225 & 0.54 & 1.443 & 6 & 0.092 & 6 \\
\hline A7 & 0.165 & 3.951 & 0.915 & 2.519 & 3 & 0.165 & 3 \\
\hline
\end{tabular}

\section{Acknowledgements}

The work was supported by the Scientific and Technological Research Program of Chongqing Municipal Education Commission under Grant No. KJ1500630, Chongqing Engineering Laboratory for Detection, Control and Integrated System, Chongqing Technology and Business University under Grant No.1556026, Scientific Research Foundation of Chongqing Technology and Business University under Grant No.2015-56-01. 


\section{References}

Abdel-Basset, M., Mohamed, M., \& Chang, V. (2018). NMCDA: A framework for evaluating cloud computing services. Future Generation Computer Systems, 86, 12-29. https://doi.org/10.1016/j.future.2018.03.014

Abourezq, M., \& Idrissi, A. (2014). Introduction of an outranking method in the cloud computing research and selection system based on the Skyline. In: 2014 IEEE Eighth International Conference on Research Challenges in Information Science (RCIS), 1-12. https://doi.org/10.1109/RCIS.2014.6861067

Afshari, A., Mojahed, M., \& Yusuff, R. M. (2010). Simple additive weighting approach to personnel selection problem. International Journal of Innovation, Management and Technology, 1(5), 511-515.

Ahn, B. S. (2011). Compatible weighting method with rank order centroid: maximum entropy ordered weighted averaging approach. European Journal of Operational Research, 212(3), 552-559. https://doi.org/10.1016/j.ejor.2011.02.017

Al-Faifi, A., Song, B., Hassan, M. M., Alamri, A., \& Gumaei, A. (2019). A hybrid multi criteria decision method for cloud service selection from Smart data. Future Generation Computer Systems, 93, 43-57. https://doi.org/10. 1016/j.future.2018.10.023

Alabool, H., Kamil, A., Arshad, N., \& Alarabiat, D. (2018). Cloud service evaluation method-based multi-criteria decisionmaking: a systematic literature review. Journal of Systems and Software, 139, 161-188. https://doi.org/10. 1016/j.jss.2018.01.038

Alabool, H. M., \& Mahmood, A. K. (2013). Trust-based service selection in public cloud computing using fuzzy modified VIKOR method. Australian Journal of Basic and Applied Sciences, 7(9), 211-220.

Alam, K. A., Ahmed, R., Butt, F. S., Kim, S. G., \& Ko, K. M. (2018). An uncertainty-aware integrated fuzzy AHP-WASPAS model to evaluate public cloud computing services. Procedia Computer Science, 130, 504-509. https://doi.org/10.1016/j.procs.2018.04.068

Alismaili, S., Li, M., \& Shen, J. (2016). Cloud computing adoption decision modelling for SMEs: from the PAPRIKA perspective. Frontier Computing, Springer, Singapore, 597-615. https://doi.org/10.1007/978-981-10-0539-8_59

Alimardani, M., Rabbani, M., \& Rafiei, H. (2014). A novel hybrid model based on DEMATEL, ANP and TOPSIS for supplier selection in agile supply chains. International Journal of Services and Operations Management, 18(2), 179211. https://doi.org/10.1504/IJSOM.2014.062000

Alshehri, M. (2019). An effective mechanism for selection of a cloud service provider using cosine maximization method. Arabian Journal for Science and Engineering, 44(11), 9291-9300. https://doi.org/10.1007/s13369-019-03947-y

Ataş, G., \& Gungor, V. C. (2014). Performance evaluation of cloud computing platforms using statistical methods. Computers \& Electrical Engineering, 40(5), 1636-1649. https://doi.org/10.1016/j.compeleceng.2014.03.017

Basu, A., \& Ghosh, S. (2018). Implementing fuzzy TOPSIS in cloud type and service provider selection. Advances in Fuzzy Systems, 2018, 2503895. https://doi.org/10.1155/2018/2503895

Brauers, W. K. M., \& Zavadskas, E. K. (2006). The MOORA method and its application to privatization in a transition economy. Control and Cybernetics, 35, 445-469.

Buyukozkan, G., Gocer, F., \& Feyzioglu, O. (2018). Cloud computing technology selection based on interval-valued intuitionistic fuzzy MCDM methods. Soft Computing, 22(15), 5091-5114. https://doi.org/10.1007/s00500-018-33174

Chakraborty, S., \& Zavadskas, E. K. (2014). Applications of WASPAS method in manufacturing decision making. Informatica, 25(1), 1-20. https://doi.org/10.15388/Informatica.2014.01

Choi, C. R., \& Jeong, H. Y. (2014). Quality evaluation and best service choice for cloud computing based on user preference and weights of attributes using the analytic network process. Electronic Commerce Research, 14(3), 245-270. https://doi.org/10.1007/s10660-014-9156-1

Costa, P., Lourenco, J. C., \& da Silva, M. M. (2013). Evaluating cloud services using a multiple criteria decision analysis approach. Service-Oriented Computing, Springer, Berlin, Heidelberg, 456-464. https://doi.org/10.1007/978-3-64245005-1_34

Ding, S., Yang, S., Zhang, Y., Liang, C., \& Xia, C. (2014). Combining QoS prediction and customer satisfaction estimation to solve cloud service trustworthiness evaluation problems. Knowledge-Based Systems, 56, $216-225$. https://doi.org/10.1016/j.knosys.2013.11.014

Ecer, F., Pamucar, D., Zolfani, S. H., \& Eshkalag, M. K. (2020). Sustainability assessment of OPEC countries: application of a multiple attribute decision making tool. Journal of Cleaner Production, 241, 118324. https://doi.org/10. 1016/j.jclepro.2019.118324 
Han Lai, Huchang Liao, Zhi Wen, Edmundas Kazimieras Zavadskas, Abdullah Al-Barakati. An Improved CoCoSo Method...

Ergu, D., \& Peng, Y. (2014). A framework for SaaS software packages evaluation and selection with virtual team and BOCR of analytic network process. The Journal of Supercomputing, 67(1), 219-238. https://doi.org/10.1007/s11227013-0995-7

Esposito, C., Ficco, M., Palmieri, F., \& Castiglione, A. (2015). Smart cloud storage service selection based on fuzzy logic, theory of evidence and game theory. IEEE Transactions on Computers, 65(8), 2348-2362. https://doi.org/10. 1109/TC.2015.2389952

Gardziejczyk, W., \& Zabicki, P. (2017). Normalization and variant assessment methods in selection of road alignment variants-case study. Journal of Civil Engineering and Management, 23(4), 510-523. https://doi.org/10.3846/ 13923730.2016 .1210223

Garg, S. K., Versteeg, S., \& Buyya, R. (2013). A framework for ranking of cloud computing services. Future Generation Computer Systems, 29(4), 1012-1023. https://doi.org/10.1016/j.future.2012.06.006

Ginting, G., Fadlina, Mesran, Siahaan, A. P. U., Rahim, R. (2017). Technical approach of TOPSIS in decision making. International Journal of Recent Trends in Engineering \& Research, 3(8), 58-64. https://doi.org/10.23883/ IJRTER.2017.3388.WPYUJ

Gireesha, O., Somu, N., Krithivasan, K., \& Sriram V. S. S. (2020). IIVIFS-WASPAS: An integrated multi-criteria decisionmaking perspective for cloud service provider selection. Future Generation Computer Systems, 103, 91-110. https://doi.org/10.1016/j.future.2019.09.053

Guo, Y. J. (2012). Theories, Methods and Expansion of Comprehensive Evaluation, Science Press, Beijing, 37.

Huang, C. Y., Hsu, P. C., \& Tzeng, G. H. (2012). Evaluating cloud computing based telecommunications service quality enhancement by using a new hybrid MCDM model. Intelligent Decision Technologies, Springer, Berlin Heidelberg, 519-536. https://doi.org/10.1007/978-3-642-29977-3_52

Hussain, A., Chun, J., \& Khan, M. (2020). A novel framework towards viable cloud service selection as a service (CSSaaS) under a fuzzy environment. Future Generation Computer Systems, 104, 74-91. https://doi.org/10.1016/ j.future.2019.09.043

Jahan, A., \& Edwards, K. L. (2015). A state-of-the-art survey on the influence of normalization techniques in ranking: Improving the materials selection process in engineering design. Materials \& Design, 65, 335-342. https://doi.org/10. 1016/j.matdes.2014.09.022

Jatoth, C., Gangadharan, G. R., Fiore, U., \& Buyya, R. (2019). SELCLOUD: a hybrid multi-criteria decision-making model for selection of cloud services. Soft Computing, 23(13), 4701-4715. https://doi.org/10.1007/s00500-018-3120-2

Ji, P., Zhang, H. Y., \& Wang, J. Q. (2018). Selecting an outsourcing provider based on the combined MABAC-ELECTRE method using single-valued neutrosophic linguistic sets. Computers \& Industrial Engineering, 120, 429-441. https://doi.org/10.1016/j.cie.2018.05.012

Ke, H. F., Chen, Y. G., \& Xia, B. (2007). Algorithm of multiple criteria decision-making based on similarity to ideal grey relational projection. Tien Tzu Hsueh Pao, 35(9), 1757-1761. (In Chinese)

Keshavarz Ghorabaee, M., Zavadskas, E. K., Turskis, Z., \& Antucheviciene, J. (2016). A new combinative distance-based assessment (CODAS) method for multi-criteria decision-making. Economic Computation \& Economic Cybernetics Studies \& Research, 50(3), 25-44.

Lakshmi, T. M., \& Venkatesan, V. P. (2014). A comparison of various normalization in techniques for order performance by Similarity to ideal solution (TOPSIS). International Journal of Computing Algorithm, 3, 882-888.

Le, S., Dong, H., Hussain, F. K., Hussain, O. K., Ma, J., \& Zhang, Y. (2014). Multicriteria decision making with fuzziness and criteria interdependence in cloud service selection. In: 2014 IEEE International Conference on Fuzzy Systems (FUZZ-IEEE), IEEE, 1929-1936. https://doi.org/10.1109/FUZZ-IEEE.2014.6891892

Lee, S., \& Seo, K. K. (2016). A hybrid multi-criteria decision-making model for a cloud service selection problem using BSC, fuzzy Delphi method and fuzzy AHP. Wireless Personal Communications, 86(1), 57-75. https://doi.org/10.1007/s11277-015-2976-Z

Li, L., Li, Y., Ye, F., \& Zhang, L. (2018). Carbon dioxide emissions quotas allocation in the Pearl River Delta region: evidence from the maximum deviation method. Journal of Cleaner Production, 177, 207-217. https://doi.org/10. 1016/j.jclepro.2017.12.205

Li, X., Yu, S., \& Chu, J. (2018). Optimal selection of manufacturing services in cloud manufacturing: A novel hybrid MCDM approach based on rough ANP and rough TOPSIS. Journal of Intelligent \& Fuzzy Systems, 34(6), 4041-4056. https://doi.org/10.3233/JIFS-171379

Liao, H. C., \& Wu, X. L. (2020). DNMA: A double normalization-based multiple aggregation method for multi-expert multi-criteria decision making. Omega, 94, 102058. https://doi.org/10.1016/j.omega.2019.04.001 
Low, C., \& Chen, Y. H. (2012). Criteria for the evaluation of a cloud-based hospital information system outsourcing provider. Journal of Medical Systems, 36(6), 3543-3553. https://doi.org/10.1007/s10916-012-9829-Z

Ma, J. (2019). Generalised grey target decision method for mixed attributes based on the improved Gini-Simpson index. Soft Computing, 23(24), 13449-13458. https://doi.org/10.1007/s00500-019-03883-x

Mu, B., Li, S., \& Yuan, S. (2014) QoS-aware cloud service selection based on uncertain user preference. In: Miao D, Pedrycz W, Izak D, Peters G, Hu Q, Wang R (eds) Rough Sets and Knowledge Technology. RSKT 2014, Lecture Notes in Computer Science, vol. 8818. Springer, Cham, pp. 589-600. https://doi.org/10.1007/978-3-319-11740-9_54

Nawaz, F., Asadabadi, M. R., Janjua, N. K., Hussain, O. K., Chang, E., \& Saberi, M. (2018). An MCDM method for cloud service selection using a Markov chain and the best-worst method. Knowledge-Based Systems, 159, $120-131$. https://doi.org/10.1016/j.knosys.2018.06.010

Noor, T. H., Sheng, Q. Z., Yao, L., Dustdar, S., \& Ngu, A. H. (2015). CloudArmor: supporting reputation-based trust management for cloud services. IEEE Transactions on Parallel and Distributed Systems, 27(2), 367-380. https://doi.org/10.1109/TPDS.2015.2408613

Opricovic, S. (1998). Multicriteria Optimization of Civil Engineering Systems. Faculty of Civil Engineering, Belgrade, 2(1), 5-21.

Paunovic, M., Ralevic, N. M., Gajovic, V., Vojinovic, B. M., \& Milutinovic, O. (2018). Two-stage fuzzy logic model for cloud service supplier selection and evaluation. Mathematical Problems in Engineering, 1-11. https://doi.org/10. $1155 / 2018 / 7283127$

Peng, X., Zhang, X., \& Luo, Z. (2019). Pythagorean fuzzy MCDM method based on CoCoSo and CRITIC with score function for 5G industry evaluation. Artificial Intelligence Review, 1-35. https://doi.org/10.1007/s10462-019-09780$\mathrm{X}$

Qu, L., Wang, Y., \& Orgun, M. (2013). Cloud service selection based on the aggregation of user feedback and quantitative performance assessment. In: 2013 IEEE International Conference on Services Computing (SCC), IEEE, $152-159$. https://doi.org/10.1109/SCC.2013.92

Ramachandran, N., Sivaprakasam, P., Thangamani, G., \& Anand, G. (2014). Selecting a suitable cloud computing technology deployment model for an academic institute: a case study. Campus-Wide Information Systems, 31(5), 319345. https://doi.org/10.1108/CWIS-09-2014-0018

Serrai, W., Abdelli, A., Mokdad, L., \& Hammal, Y. (2016). An efficient approach for Web service selection. In: 2016 IEEE Symposium on Computers and Communication (ISCC), IEEE, 167-172. https://doi.org/10.1109/ISCC.2016.7543734

Sidhu, J., \& Singh, S. (2019). Using the improved PROMETHEE for selection of trustworthy cloud database servers. The International Arab Journal of Information Technology, 16(2), 194-202.

Silas, S., Rajsingh, E. B., \& Ezra, K. (2012). Efficient service selection middleware using ELECTRE methodology for cloud environments. Information Technology Journal, 11(7), 868. https://doi.org/10.3923/itj.2012.868.875

Singh, S., \& Sidhu, J. (2017). Compliance-based multi-dimensional trust evaluation system for determining trustworthiness of cloud service providers. Future Generation Computer Systems, 67, 109-132. https://doi.org/10.1016/ j.future.2016.07.013

Somu, N., Kirthivasan, K., \& Sriram, V. S. (2017). A rough set-based hypergraph trust measure parameter selection technique for cloud service selection. The Journal of Supercomputing, 73(10), 4535-4559. https://doi.org/10. 1007/s11227-017-2032-8

Sun, L., Dong, H., Hussain, F. K., Hussain, O. K., \& Chang, E. (2014). Cloud service selection: State-of-the-art and future research directions. Journal of Network and Computer Applications, 45, 134-150. https://doi.org/10. 1016/j.jnca.2014.07.019

Varghese, B., \& Buyya, R. (2018). Next generation cloud computing: new trends and research directions. Future Generation Computer Systems, 79, 849-861. https://doi.org/10.1016/j.future.2017.09.020

Wen, Z., Liao, H. C., Zavadskas, E. K., \& Al-Barakati, A. (2019). Selection third-party logistics service providers in supply chain finance by a hesitant fuzzy linguistic combined compromise solution method. Economic Research-Ekonomska Istrazivanja, 32(1), 4033-4058. https://doi.org/10.1080/1331677X.2019.1678502

Wu, X. L., \& Liao, H. C. (2018). An approach to quality function deployment based on probabilistic linguistic term sets and ORESTE method for multi-expert multi-criteria decision making. Information Fusion, 43, 13-26. https://doi.org/10.1016/j.inffus.2017.11.008

Yang, Y., Liu, R., Chen, Y., Li, T., \& Tang, Y. (2018). Normal cloud model-based algorithm for multi-attribute trusted cloud service selection. IEEE Access, 6, 37644-37652. https://doi.org/10.1109/ACCESS.2018.2850050 
Han Lai, Huchang Liao, Zhi Wen, Edmundas Kazimieras Zavadskas, Abdullah Al-Barakati. An Improved CoCoSo Method...

Yazdani, M., Wen, Z., Liao, H. C., Banaitis, A., \& Turskis, Z. (2019a). A grey combined compromise solution (CoCoSoG) method for supplier selection in construction management. Journal of Civil Engineering and Management, 25(8), 858-874. https://doi.org/10.3846/jcem.2019.11309

Yazdani, M., Zarate, P., Zavadskas, E. K., \& Turskis, Z. (2019b). A combined compromise solution (CoCoSo) method for multi-criteria decision-making problems. Management Decision, 57(9), 2501-2519. https://doi.org/10.1108/MD-052017-0458

Yu, P. L. (1973). A class of solutions for group decision problems. Management Science, 19(8), 936-946. https://doi.org/10.1287/mnsc.19.8.936

Zanakis, S. H., Solomon, A., Wishart, N., \& Dublish, S. (1998). Multi-attribute decision making: a simulation comparison of select methods. European Journal Of Operational Research, 107(3), 507-529. https://doi.org/10.1016/S03772217(97)00147-1

Zavadskas, E. K., Turskis, Z., Antucheviciene, J., \& Zakarevicius, A. (2012). Optimization of weighted aggregated sum product assessment. Elektronika ir elektrotechnika, 122(6), 3-6. https://doi.org/10.5755/j01.eee.122.6.1810

Zhao, L. P., Ren, Y. Z., Li, M. C., \& Sakurai, K. (2012). Flexible service selection with user-specific QoS support in serviceoriented architecture. Journal of Network and Computer Applications, 35(3), 962-973. https://doi.org/10. 1016/j.jnca.2011.03.013

Zolfani, S. H., Chatterjee, P., Yazdani, M. (2019). A structured framework for sustainable supplier selection using a combined BWM-CoCoSo model. In: International Scientific Conference in Business, Management and Economics Engineering. Vilnius, Lithuania, pp. 797-804.

The article has been reviewed.

Received in January 2020; accepted in October 2020.

This article is an Open Access article distributed under the terms and conditions of the Creative Commons Attribution 4.0 (CC BY 4.0) License (http://creativecommons.org/licenses/by/4.0/). 